\title{
The functional approach in comparative socio-legal research: reflections based on a study of plural work regulation in Australia and Indonesia'
}

\author{
Petra Mahy*
}

\begin{abstract}
This paper examines the potential use and limits of Zweigert and Kötz's classical functional approach in comparative law for an empirical socio-legal research project. The project involves a comparison of the formal labour laws and informal norms and institutions which regulate restaurant work in the cities of Melbourne, Australia, and Yogyakarta, Indonesia. The paper argues that the functional approach is a necessary but incomplete method for overcoming the many issues of comparability between the two research sites; the method requires both extension of its analytical steps and explicit explanation of its limitations.
\end{abstract}

\section{Introduction}

Comparative socio-legal research more often turns to the methods of legal anthropology and the concept of legal culture than it does to traditional comparative law methods (Banakar and Travers, 2005, pp. 240-24I). Disregarding this trend, this paper, which reflects on the results of empirical qualitative studies of plural work regulation in Australia and Indonesia, evaluates the usefulness of the functional approach as formulated in the classic chapter on comparative law method by Zweigert and Kötz (I998, pp. 32-47). The aim of the paper is to lay the foundations for an explicit and systematic comparative analysis of the two sets of empirical data, hence responding to the calls of socio-legal theorists for comparative research that moves beyond mere 'butterfly collecting' (Cotterrell, 20I2, p. 40) or 'comparison by juxtaposition' (Nelken, 2005, p. 248).

For this project, interview data were collected on the substance of, and interactions between, the formal laws and informal norms and institutions that regulate work arrangements in restaurants and other eateries in two very different cities: Melbourne, Australia, and Yogyakarta, Indonesia. ${ }^{2}$ This was a pilot project aimed at initial exploration of the topic and to discover whether the planned semistructured interview methodology would be successful in examining this particular phenomenon in such different country contexts. The project was inspired by the observation that, while there has been much attention paid recently to the failure of labour law to protect many workers around the world (e.g. Davidov and Langille, 2006; Fudge et al., 20I2; Teklè, 20I0), there is far less understanding of the informal norms and institutions that, in the absence of or in interaction with labour laws, do govern the work arrangements and practices of these workers (Cooney et al., 20I4; Mitchell et al., 20I4; Sportel, 20I3; Tsikata, 20II; Harriss-White, 20Io, p. I79). Meanwhile,

* SOAS, University of London, UK. E-mail: petra.mahy@soas.ac.uk.

I This paper draws on research that was funded by a collaborative University of Melbourne Interdisciplinary Seed Grant for the project entitled 'How Are Low Protection Workers Regulated? A Pilot Study in Australia and Indonesia' (Sean Cooney, Martina Boese, John Howe, Petra Mahy, Richard Mitchell and Joo-Cheong Tham) (2013). I particularly thank Richard Mitchell, Naomi Creutzfeldt and the anonymous reviewer for their comments on earlier drafts of the paper.

2 For the results of the study on Yogyakarta, Indonesia, see Mahy et al. (forthcoming). 
various policy initiatives such as those of the International Labour Organisation (ILO) continue to promote the formalisation of informal work around the world with little emphasis placed on the importance of understanding the role and effects of informal norms and their interactions with formal labour laws. ${ }^{3}$

The studies in Melbourne and Yogyakarta have produced rich datasets in which restaurant workers from a range of establishments described the various aspects of their work arrangements and explained how these were put in place and their perspectives on the validity of these arrangements. As such, the results of the project appear far more significant than merely providing a test of the merits of the methodology used. Initial impressions of the data suggest that there are a number of overlaps and similarities in the findings in the two cities and that a set of shared concepts and understandings is emerging from the data. Comparison of the two sets of results may allow wider generalisations to be made about the content and effects of informal norms and their interactions with formal labour law. Therefore, the project's potential may be enhanced by producing an explicit comparative analysis of the two cases.

There are four main aspects of the project that present particular challenges for comparison. First, it seeks to compare research findings from two urban contexts that are located within countries that are probably as culturally and economically different as any two neighbouring countries in the world. This means that there are countless contextual variables to be taken account of which may impede meaningful comparative analysis. Second, while all comparative projects have the potential for bias, in comparing research conducted in a developed country with research conducted in a developing country, the risk of ethnocentrism affecting the analysis is particularly high.

Third, the project is framed within a 'regulation' approach (Parker et al., 2004; Frazer, 2014), which takes into consideration the plurality of sources of social ordering - that is, both formal laws produced by the state as well as informal (or non-state) norms and institutions. This approach recognises that informal norms and institutions often play complementary or even substitutive roles when formal regulation is absent or ignored (Helmke and Levitsky, 2004; Chiba, 1998). This raises challenging issues of consistently defining 'law' and 'non-law', and making the same causal assumptions about links between laws/non-laws and behavioural outcomes across the two cases.

Fourth, this research broadly falls within the area of labour law, which in recent times has been undergoing much soul searching about its disciplinary scope, functions and previously assumed universality. These debates include questions about the applicability of models of the employment relationship which evolved in the West to so-called 'non-traditional' work generally and to developing country contexts specifically (see e.g. discussion in Davidov and Langille, 20I I; Fudge et al., 20I2). This means that 'labour law' and its constituent elements, perhaps even more so than other areas of law, are certainly not a model that can be taken for granted as being sufficiently similar across jurisdictions for the purpose of comparison.

As noted, socio-legal scholars have a number of tools to draw on in attempting to overcome complex issues of comparability; the notion of 'legal culture' is often seen as a primary template for comparative socio-legal research (Nelken, I997; Cotterrell, 20I2, p. 46), while others turn to the study of legal transplants, legal consciousness or comparative legal history. On the face of it, however, none of these options presents a solution to the complexities of comparability found in this particular micro-level point-in-time research project. A potential method (or at least a starting point) does appear to be offered by the functional approach, found specifically in comparative law, but also in comparative sociology. In brief, the functional approach requires the following steps: identify a shared social problem in each place under consideration and define it without

3 See e.g. ILO, 20I3; and ILO Recommendation no. 204 Concerning the Transition from the Informal to the Formal Economy, 20I5. 
recourse to legal terms, find and describe the 'legal' and 'extra-legal' solutions that arise in relation to the problem in each system, identify similarities and differences between the solutions, build a conceptual language capable of discussing all the cases, find explanations for similarities and differences in the wider context and, finally, critically and normatively evaluate the findings (Zweigert and Kötz, I998, pp. 32-47). Hence, the functional approach is very suited to micro-level projects due to its focus on particular social problems and their solutions. In addition, it is not, as is commonly thought, restricted to consideration of formal laws and so appears to lend itself to wider socio-legal research.

While the functional approach, when formulated as this series of steps, seems straightforward and has been sometimes claimed to be the method in comparative law, in recent times it has become somewhat unfashionable. Many fundamental critiques have been proffered against the functional approach, especially regarding the 'constructed' nature of social problems, the artificial stripping back of context, misplaced positivist assumptions about the relationship between law and society (Frankenberg, 1985; Legrand, 2003) and the production of ethnocentric and 'Orientalist' results (Ruskola, 2002). The questions to be resolved in this paper are whether these critiques of the functional method are indeed sustained and, if so, whether the drawbacks they identify might be overcome in this particular empirical socio-legal project.

I follow the lead of some other researchers (Husa, 2003; Samuel, 20I4; Valcke, 20I 2; Adams and Griffiths, 20I2) in seeing functionalism as a very useful beginning point in the comparative process, provided that its inherent limitations are recognised and that certain additional analytical steps are taken. These limitations include the impossibility of drawing strong causal connections between law/ norms and behaviour, and between the differences observed and the wider social context, as well as the ultimate futility of a search for completely unbiased comparative concepts. Both 'inner' and 'outer' perspectives are required in order to shed light on causal connections. An optional additional step of examining legal consciousness is also potentially beneficial to the analysis.

The structure of this paper is as follows. I begin by explaining the empirical project and its aims and methods in more detail, and also provide a brief description of the preliminary research findings in Yogyakarta and Melbourne. I then discuss the defining of the social problem within the functional approach, and then the step of identifying the 'legal' and 'extra-legal' solutions to that problem. In the next sections, I examine the particular drawbacks with the functional approach - the making of positivist assumptions about the links between law and behaviour, the challenge of developing a conceptual language that does not perpetuate legal ethnocentrism, and then the use of context and causation in analysis. I also discuss the possibility of building on the functional comparative approach to examine legal consciousness and collective narratives of legality. Finally, I reflect on the potential for policy formulation arising from this comparative research.

\section{Project aims}

Two main discovery questions underpin the research in the two cities: first, what informal norms and institutions play a role in regulating work arrangements in restaurants; and, second, how do these informal modes of regulation interact with formal labour standards laws? In other words, the research seeks to understand what is actually regulating work arrangements across a range of restaurants, and how this might differ from the assumptions often made about the effects of state labour laws. Comparative labour law has tended to be dominated by doctrinal law studies (see e.g. Finkin, 20I5) and, to date, there has been only limited empirical labour law research conducted (Deakin, 2010, p. 309; Ludlow and Blackham, 2015). Labour law scholars, in contrast to some other areas of law, have been slow to debate the limits of law and the existence of legal or regulatory pluralism (Frazer, 20I4). Meanwhile, other disciplines including anthropology, labour geography and gender studies have produced numerous works on 'informal employment' in both developed 
and developing economies, but these have rarely discussed the interface between informal work regulation and formal labour law (see the extensive literature review in Mahy et al., forthcoming). Taking a regulatory approach to labour studies, which includes recognition of informal types of ordering, should assist with identifying how the law actually operates and its effects on work arrangements and the social conditions of workers (Frazer, 2014).

Twining (2009) has argued that socio-legal studies of pluralism have tended to be conceived narrowly and to be mainly descriptive with little practical relevance. They rarely venture into the realm of 'justification, legitimation and evaluation' (Twining, 2009, p. 503). In contrast, these research projects in Yogyakarta and Melbourne have an evaluative component concerned with both insider and outsider views of the effects of laws and norms on work arrangements and workers' well-being. It is likely that the research will have policy implications for efforts to formalise informal work, particularly relating to the programmes of the ILO. The value of this comparative study in the two very different locations must ultimately be found in the uncovering and explaining of at least some unexpected similarities, but also in evaluating the different outcomes for workers and challenging the dominant focus on exporting Western labour regulation models as solutions to developing country problems.

\section{Empirical research methods}

The data collection methods for this project were, of course, designed to suit these aims. The restaurant sector was selected for the project, as it tends to include both formally and informally regulated businesses in both Indonesia and Australia. In Yogyakarta and Melbourne, workers were interviewed in a range of restaurants and other eateries covering different-sized businesses and types and expense of food served, etc. The workers were asked about their personal backgrounds, the full scope of their work arrangements including recruitment, contracts or agreements, remuneration and other benefits, discipline, social security, knowledge of labour laws and standards, and their motivations for preferring or accepting more formally or informally regulated work arrangements. Thirty interviews were conducted in each place during 2013 and 2014. These were, as mentioned, semi-structured interviews arranged around the same set of questions in each city, but respondents were also given opportunities to describe issues that they thought were important in their workplace. The interviews in Yogyakarta were conducted in Indonesian, and the interviews in Melbourne in English. Due to practical and ethical considerations, different participant recruitment methods were used in the two cities. In Yogyakarta, workplaces were approached directly and permission was sought to speak to workers, while, in Melbourne, advertisements were placed and most participants were interviewed in a neutral location. Nonetheless, in both places, a good mix of respondents was obtained with respect to gender, ethnicity, migrant status and job role. Each set of interviews has been transcribed and is being analysed separately using qualitative data analysis software for similarities and differences across the interviews.

\section{Preliminary findings}

The analysis of the interview results is still ongoing, so the observations presented here are preliminary impressions. In Yogyakarta, the research found quite a clear spectrum of formality in the regulation of work in restaurants, ranging from enterprises that followed Indonesian labour laws closely, through to a wide band of businesses that mixed formal laws and informal norms in different ways, through to places where informal norms were dominant. These informal norms tended to be labelled as kekeluargaan or 'family-ness', which covered a bundle of interrelated ideas including: reciprocity, patron-client or parent-child-type relationships, flexibility in terms of rules, leniency towards a worker's family and social responsibilities, the expectation that a worker 
can approach the business owner about their personal and financial problems, as well as laughing and joking in the workplace. 'Institutions of social identity' (Harriss-White, 20I0) including ethnicity and gender were clearly important aspects of informal regulation but rarely constituted any hard and fast rules. Respondents reported that, in some workplaces, religious values were important aspects to their work arrangements particularly where business owners felt a moral obligation to encourage or ensure the piety of their workers. Particularly in the middle band of the spectrum, it was possible to discern the modification of formal labour laws according to local values and reasoning. For example, paying below-minimum wage levels was often rationalised if the worker was also being provided with accommodation and meals by the business owner. In Yogyakarta, informality in work regulation appeared to be supported by workers' consistent articulation of narratives about the flexible applicability of labour law.

In Melbourne, the interviewees also reported a range of formally and informally regulated practices. While many of the interviewees labelled themselves as 'casual' workers (casual work being one of the major forms of legal non-standard employment in Australia), their actual conditions were determined much more informally. In informally regulated workplaces, unpaid trials, being paid below the minimum wages and paid cash-in-hand (i.e. without declaring wages for taxation purposes) were common. Such informal norms could be traced across business clusters, with, for example, workers in Asian restaurants in particular reporting quite uniform, below-minimum wages. Ethnicity and gender were important factors in many of the work arrangements, but none of the workers reported any religious aspects to their situation. Some respondents described fictive kinship within their workplaces, such as with workers invited to sit down to 'family' meals with business owners and other employees. Many said that personal integrity and feelings of social debt towards their employer were factors in their acceptance of informal regulation of their work arrangements. The distribution of tips, which is not regulated by law at all, was a particularly interesting site of informal norms, with many respondents reporting a disjuncture between what they thought 'ought' to be done and what 'is' done in practice.

This brief overview of the findings in the two cities indicates many differences, but also some intriguing similarities in terms of the actual content of the informal norms and with respect to the ways that they interact with the formal labour laws in each country. The question to be addressed in this paper is to what extent these findings may be said to be validly comparable when approached through the functional method.

\section{Comparability and the 'social problem'}

As noted above, this project involves setting up an explicit binary comparison between empirical socio-legal research conducted in Yogyakarta, Indonesia, and Melbourne, Australia. Despite being near neighbours, the political, legal, economic and cultural differences between Australia and Indonesia are obvious; at a very general level, Australia has a developed economy, a common-law heritage, a relatively small population with a small informal economy, while Indonesia is a developing country, broadly has a civil-law heritage, the fourth largest population in the world and a very large informal economy. The cities of Yogyakarta and Melbourne have very different demographics and heritages.

Both Indonesia and Australia have extensive labour law and industrial dispute-resolution systems. Although the specifics of the laws and formal institutions in the two countries are certainly different on various levels, due to international diffusion of labour laws and standards particularly through the efforts of the ILO and other globalising factors, it can also be said that there are general similarities in terms of content and issues covered. A recent quantitative study shows that, since the early 2000s, when Indonesia's labour laws were dramatically reworked, the combined protective effect of the labour laws on the books in Indonesia and Australia has actually 
been quite similar. They each have strengths in different areas of worker protection but overall close aggregate scores (Anderson et al., 20I5). This accounts for the law in the books, but implementation of these labour laws is certainly not the same - these countries have vastly different rankings on rule-oflaw indices - and, once these are taken into account, Indonesia is shown to have lower levels of worker protection than Australia (Anderson et al., 2015).

One could continue enumerating the differences between the two research sites indefinitely. It is a truism that one cannot usefully compare things that are essentially dissimilar or incommensurable. There are, therefore, significant issues of comparability to be overcome if a comparison between the two studies is to be valid. For Zweigert and Kötz (I998), one should not begin a comparison with legal categories that are likely to be based on home jurisdiction preconceptions, but rather legal solutions are said to be comparable if they relate to the same social problem. In their words, 'the legal system of every society faces essentially the same problems, and solves these problems by quite different means though very often with similar results' (Zweigert and Kötz, I998, p. 34). In this way, through isolating the social problem, the complexity of contextual differences between cases is reduced in a controlled way and a common point of entry into different legal systems is provided (Valcke, 20I2). The different solutions that arise from the same social problems are said to be 'functional equivalents'. The social problem, once identified, should be stated in purely social terms so as to avoid the legal preconceptions held by the researcher (Zweigert and Kötz, I998, p. 35).

In this project, the social problem can be formulated as the need to arrange work in restaurants so as to fulfil the requirements of the business owner to deliver food and service to customers and make a profit while at the same time ensuring a certain level of satisfaction and benefits to workers. The social problem has been carefully defined in order to avoid the traditional idea of a dyadic relationship between employer and employee, and the associated assumption that the main role played by labour law is to mediate that relationship. In so doing, I aim to recognise the reality of multiple significant relationships both within the workplace and between individuals in the workplace and the wider community. It is also intended to capture the many constituent aspects of work arrangements, covering the full range from recruitment through to ending the work arrangement, without presupposing the existence of a legal contract of employment.

However, one of the major critiques of the functionalist approach holds that social problems are not necessarily the same, but are rather artificially 'constructed' as being the same (Frankenberg, I985; Whitman, 2003, p. I4; Legrand, 2003, p. 292). In fact, Zweigert and Kötz (I998, pp. 39-40) did not take the position that all social problems will have exact equivalents in other societies, or that all social problems will necessarily produce solutions. They particularly cautioned against comparing problems that are 'heavily impressed by moral views or values' such as in family law or inheritance or problems that are overly political or rooted in the particularities of religion or history. Oddly, it is quite rare for functionalists to explicitly define the social problem that they are addressing (Michaels, 2006, p. 34I). Leyland (2002, p. 2I6), in a comparative study of public law in Italy and the UK, found that 'the attempt to approach the distribution, exercise, and containment of state power' served as the social problem. Valcke (2012, p. 33) observed in her study of French and English contract law that 'mismatches between subjective intention and objective declaration, or the concern to consecrate yet also discipline party intention' were common to both places. Adams and Griffiths (2012) found enough similarity in modern European health-care systems and the problem of how to approach end-of-life decisions to be a basis for comparison of euthanasia laws and related practices.

I agree with the view that it is quite conceivable for a social problem to exist in one place and not in another - or for particular behavioural patterns to exist but not be viewed as a 'problem'. Whether there is a shared social problem in different societies should be a matter of careful empirical observation and judgment, and is more likely to be validly claimed in situations relating to basic human needs and aspects of modern economic life. In this case, I observed that restaurants and 
other eateries in Yogyakarta and Melbourne have essential similarities in aims, physical structures and business organisation, and share the same need for labour even if there are variations in terms of numbers of workers and exact work roles. More generally, there is also the basic shared economic reality of the need for capital growth (profit) alongside the distributive problem of needing to provide benefits to labour.

\section{VI. 'Legal' and 'extra-legal' solutions}

Having identified the social problem, the next step in the functional approach is to describe the solutions provided by the systems in each place. The solutions to the social problem are not limited by particular areas of law. Hence, in this project, I am not bound by labour law solutions to the problem, but should also take account of other sources of regulation including social security, taxation and business registration requirements that converge on the particular social problem (see Frazer, 20I4, p. 9).

Zweigert and Kötz, very relevantly to this project, acknowledge that the solutions to particular problems may not necessarily be 'legal', but may be produced by 'extra-legal' norms and institutions. In defining 'extra-legal', they include practices that supersede or bypass legislation and judge-made law as well as the unwritten rules of commercial practice. They explain that a social problem in one place may have legal solutions, while, in another, it may be solved by a custom or social practice (Zweigert and Kötz, I998, p. 35). As an example of an 'extra-legal' solution, they cited the growth of title insurance companies in the US that had emerged in reaction to a vacuum in the legal property titling system.

This socio-legal aspect of Zweigert and Kötz's functional method has been largely overlooked by comparatists. A literature search has discovered few studies that have explicitly used the functional comparative method and included both 'legal' and 'extra-legal' solutions to a social problem. One exception is Adams and Griffiths (2012) in their comparative study of euthanasia laws that included consideration of 'para-legal' sources of law, which in their research context meant internal organisational rules and professional guidelines. According to Michaels (2006, p. 364), comparative lawyers' tendency to only take account of formal legal rules and their application is 'a flaw in practice, not in method'. This tendency may be at least partly attributed to what I consider to be a fundamental misinterpretation of this aspect of the functional comparative method by some critics. Frankenberg (I985, p. 438), in his critique of functionalism, wrote:

'There is nothing outside legal texts and institutions for functionalists. Law as consciousness or cluster of beliefs is beyond a perspective that focuses on the instrumental efficiency of legal regulations. Functionalism has no eye and no sensitivity for what is not formalised and not regulated under a given legal regime. What started out as a fascinating hypothetical experiment has turned into a rather dry affirmation of legal formalism.'

Legrand (2003, p. 292), also in a prominent critique of the functional approach, and quoting Frankenberg, agreed that functionalism does not look beyond the formal law. Brand (2007, p. 4I0) seems to be making a similar assumption where he writes that the functional approach allows a comparatist to stay 'within the familiar legal framework, rather than having to venture into sociological research'. These commentators were referring to the dominant body of comparative law research, which does focus on the formal law. The existence of this literature, however, does not of itself place any impediment to fully using the method as set out by Zweigert and Kötz, and taking a particularly socio-legal and/or regulatory approach to considering the solutions that arise in relation to a particular social problem. 
The inclusion of 'extra-legal' solutions in the functional approach, however, does complicate matters. Zwiegert and Kötz take the distinction between 'legal' and 'extra-legal' solutions for granted. But the problem of where to draw the 'definitional stop' (Twining, 2009) between law and non-law has been a problem grappled with by legal pluralism scholars for decades. Many legal anthropologists have argued that 'law' does not need to emanate from the state but may be produced within much smaller social units (beginning with the work of Malinowski (I926)). This labelling of many different types of social or economic ordering as law has raised questions about where to draw a line between law and social practice (Merry, I988, p. 878). A current leading approach is to turn to the idea of regulatory pluralism (which recognises multiple sources of social ordering) rather than legal pluralism (which focuses on multiple sources of 'law'), while at the same time retaining an appreciation for the importance and distinctiveness of state law (Tamanaha, 2008; Parker et al., 2004). I adopt this approach in this project, but prefer the terms 'formal' and 'informal', where 'formal' refers to state laws and institutions that may have a greater degree of intentionality in terms of their relationship to the social problem and where 'informal' covers non-state-derived forms of regulation that may arise more 'organically' through repeated practices and negotiation in relation to the problem. This helps to avoid the problem of implicitly only attributing legality to state law.

There still remains the problem of the tendency to conceptualise a hierarchy of regulation in which the term 'informal' is taken to cover an inferior residual category of everything that is not formal. This tendency obscures both the complexities of how people perceive the 'different strands of structuring forces' in their lives and the high importance that informal forms of regulation can have in producing social order and facilitating economic activity (Benton, I994, p. 237). Another erroneous assumption often made is that informal forms of regulation are necessarily 'unstructured' and/or 'chaotic'. Such assumptions have been shown to be conceptually unsound and have been a powerful impetus for government interventions that then resulted in policy disasters (Guha-Khasnobis et al., 2006). Hence, this project needs to give appropriate weighting to both the formal and informal solutions that are identified in the interview material. The project should not assume that problems should be solved by formal rather than informal means, and it should be prepared to compare the formal and informal solutions on equal footing. In addition, the comparative analysis of the solutions in the two cities should be open-minded and privilege neither difference nor similarity, but be ready to discover either situation (Cotterrell, 20I2, p. 39).

Zweigert and Kötz did not clearly envision the use of empirical data in seeking the 'legal' and 'extra-legal' solutions to the chosen social problem. Instead, they merely hint that the comparatist should explore the chosen legal systems as deeply as possible and use creative thinking to find all the possible solutions. The implications of using the kind of empirical data as collected in this project is dealt with in the following section on positivism.

\section{Positivist links between regulation and behaviour}

Critiques of the functionalist method point out that it rests on the positivist assumption that law (and other 'extra-legal' solutions) arise from particular social problems, namely that 'law is determined by social problems' or at least that law and social problems are co-determined (Frankenberg, I985, p. 437). This requires an evolutionary vision where 'law progressively adapts to social needs or interests, or develops through interacting with its environment' (Frankenberg, I985, p. 438). So, it is argued, functionalism artificially separates law from society, and takes an essentially technical and utilitarian approach to analysis (Legrand, 2003).

Of course, this functionalist vision of law contradicts the empirical reality that 'rules only ever imperfectly guide behaviour and sometimes not at all' (Galligan, 2007, p. 207). Particular laws may do things other than directly regulate social behaviour or be functionally related to a current 
social problem - for example, they may signal to the international community, produce a discourse, create a framework of expectations or produce a 'shadow' under which private parties may bargain (Mnookin and Kornhauser, I979) or they may just be leftovers from earlier times and do nothing (Watson, 2000). Laws may also have more than one function, or they may have been put in place with the intention of performing a particular function but, over time, that function may change. It seems to me that the fact that some laws do not have direct links to social problems or that laws may serve more than one function at once or have no function at all is not actually a critical problem to the functionalist method because such laws are not included in the analysis. That is, the functionalist is only interested in comparing the laws that are in play in any particular situation and should exclude any that might have been intended to respond to a particular problem but in practice do not. If a researcher wanted to compare laws that have no behaviour regulating function in relation to the selected social problem, then they would need some other comparative approach.

That said, there remains the problem of assuming a positivist link between patterns of behaviour and regulation. In both sets of empirical data in this project, a causal leap needs to be made between the work arrangements documented through the interview data and the assumption that it is a particular form of regulation that causes it. In situations of reference to law, causation between the work arrangements described in the interviews and their origin can be more easily inferred, such as where the detail of a particular labour law was exactly or closely reproduced in reality. This can be more complicated where law may be guiding behaviour indirectly, such as where it sets standards even if they are not fully implemented. For example, as noted above, the payment of the minimum wage in Indonesia is a legal requirement that most people are aware of but it is often interpreted loosely when other benefits are also provided to employees. That is, the law has some effect but this occurs in combination with non-legal values and reasoning. Further, where the law has formalised a pre-existing informal practice it can become impossible to determine whether complying behaviour is caused by the law, the pre-existing informal regulation or both.

Identifying 'norms' is also rather complicated. A distinction may be drawn between what actors subjectively think 'ought' to be done (the 'internal' aspect of a norm) and what 'is' commonly done in practice (the 'external' aspect) (Hart, I96I, p. 8I; Kelsen, I967). Banakar (20I5, p. 2 I6) writes that the 'external' aspect of social norms can be 'revealed through tangible and observable behaviour and can be studied by employing empirical methods'. However, Baier (2013, p. 63) warns that mere recurrent patterns of behaviour are not necessarily the result of norms and, equally, norms (as 'ought') do not necessarily result in particular behaviour. Further, normative openness is possible where many types of social ordering are acceptable. In cases where there are competing norms, an actor may rationalise a choice between them according to their own individual interests.

Beyond the problem of empirically identifying solutions to the social problem, one could easily incorrectly assume that both systems have similar conceptions of law and non-law, and that they both share positivist ideas about the links between laws/norms and outcomes (Samuel, 20I4, p. 80). Hence, rendering this process of inference comparable across the two cases is potentially even more problematic. It appears that combined 'outer' and 'inner' understandings of the social problem (Samuel, 2014, p. I06) may assist with overcoming this issue of comparability. The data collected in this project can support analysis of an 'inner' understanding of how workers view their circumstances and, in particular, how they viewed any links between their own work arrangements and formal labour laws and informal norms, and indeed if and how they make a distinction between formal and informal regulation. In some cases, they were able to explain what 'ought' to be the case and what was actually occurring in practice. This introduces a subjective element to the analysis, which of course has its own weaknesses, as workers in particular may not 
know how their work arrangement was determined by their employer, ${ }^{4}$ but it does assist with the drawing of more defensible causal linkages.

For example, many of the interviewees in Yogyakarta expressed a very clear view that their work arrangements were not affected by formal law, but instead were justifiably arranged according to norms of kekeluargaan or 'family-ness'. Similarly, in Melbourne, a number of interviewees reported that it is a 'secret rule' that everyone who works in restaurants in Chinatown is paid a particular hourly rate, hence the source of this particular practice (at least subjectively) is made clear. Paying attention to the 'inner perspective' will not necessarily establish a positive link between behaviour and regulation, but it should help avoid assuming that there are similarities in the links between law/norms and outcomes in the two research sites. Further, it must be acknowledged that conclusive identification of norms will probably not be possible given the limitation of the moderately small number of interviews (thirty) conducted in each city for this project.

\section{Creating common concepts and avoiding ethnocentrism}

Once the social problem and its 'legal' and 'extra-legal' solutions have been identified and positivist assumptions addressed, the next step in the functional approach is to develop a 'special syntax and vocabulary' for discussing the comparative analysis. That is, the researcher needs to build up categories from the empirical data in both cases and create a common conceptual language that is flexible and wide enough to encompass the solutions provided by each system under consideration. According to Zweigert and Kötz (I998, p. 43), this analytical stage 'involves adopting a new point of view from which to consider all the different solutions'. This is another aspect of the attempt to eradicate preconceptions and ethnocentrism on the part of the researcher. This should be done through 'dialectical interchange' so that researchers become aware of their cultural biases and the problems of translation (Nelken, 2005, p. 247). Adams and Griffiths (20I2, p. 286) suggest that the comparative researcher should 'proceed in a spirit of conceptual tentativeness, seeking continuously to smoke out normative preconceptions'.

To illustrate what this process might involve in the case of the present project, I consider the term kekeluargaan (family-ness), which emerged strongly in the Yogyakarta interviews. The creation of fictive family relationships in the workplace was also mentioned by some of the Melbourne restaurant workers. Kekeluargaan is clearly a context-specific term that is indigenous to Indonesia and cannot be used to describe the Melbourne situation. A more general concept of 'fictive kinship' might serve as an umbrella term that would cover the situation in both places and, in doing so, would highlight similarities across the two cases. Choosing to translate kekeluargaan into English and into the broader conceptual term of 'fictive kinship', however, will necessarily result in the loss of the Indonesian specificity of the term, and analysis might become skewed towards a finding of similarity rather than of difference.

This problem of translation in the act of socio-legal comparison has, of course, been long recognised and debated (Moore, I969), although Zweigert and Kötz themselves do not explicitly recognise it within their direction to develop a common vocabulary. It is clear that descriptive and analytical language can never be completely free of bias, even after progressing through a dialectic process (Puchalska-Tych and Salter, I996). In the example given here, I could continue considering different conceptual options for kekeluargaan, including keeping the term in the vernacular, but in the end I may need to accept that my analysis is being conducted in English, and that I am drawing on my own analytical abilities (and prejudices) and that this will always

4 Employers were not included in the data collection in either the Melbourne or Yogyakarta projects due to the supposition that they would be less likely than workers to speak frankly about informal employment practices. 
skew the results. One can only recognise this reality and 'be self-reflective and self-critical' (Frankenberg, I985, p. 44I) and explicitly declare one's subjective position.

Given that this project seeks to compare conditions in a city located in a 'developed' nation with a city located in a 'developing' nation, there is a political risk to translation and bias beyond mere conceptual comparability. As Baxi (2003) persuasively argued, a danger lies in attributing too much significance to the colonial moment and engaging in progress narratives when describing developing or post-colonial countries' legal systems. The developing country can, he argued, very easily end up being depicted as the 'exotic other'. Ruskola (2002) proffered a similar analysis of many Western studies of law in China as being examples of 'Legal Orientalism', particularly those which take an extreme functionalist approach that insist on finding exact equivalents. This risk arises in this project with Australian researchers comparing Australia with Indonesia as a developing Asian country, but also because it is broadly a labour law project. Progress narratives have tended to underpin understandings of labour law. It is often assumed that developing countries are on the same industrialisation trajectory as Western developed economies, with labour law expected to play the same role (see discussion in Mitchell et al. (2014) and Teklè (20I0)). As noted, the ILO continues to pursue policies of bringing all or as many workers as possible within formal (and usually Western-influenced) labour regulation. In the case of this project, every effort will need to be made to ensure that the 'legal' and 'extra-legal' solutions found in each place are treated equally and that any teleological assumptions about one case providing the pattern or future of the other will need to be carefully avoided.

\section{Context and causation}

It is certainly true that, in focusing on the social problem and its solutions at the micro level, the functional approach begins by excluding all of the systemic, societal, moral, cultural and historical differences between the cases being compared. Frankenberg (I985, p. 440) particularly disdains this aspect of the functional approach, arguing that 'the functionalist negates the interaction between legal institutions and provisions by stripping them from their systemic context and integrating them in an artificial universal typology of "solutions". He also writes that functionalism requires the contradictory operation of both suppressing the context and considering it. Indeed, in Zweigert and Kötz's method, the solutions that arise in relation to a particular social problem should first be freed from the context of their own system, but then afterwards we need to ask why societies may meet the same need in similar or different ways. The answers to this 'may lie anywhere in the whole realm of social life, and one may have to venture into the domains of other social sciences such as economics, sociology or political science' (Zweigert and Kötz, I998, p. 44).

This stripping-away of context and then later considering it for explanatory purposes is certainly artificial, but it does serve as a useful heuristic tool, provided that it is recognised as such. The advantage, I think, of starting with the problem and then selectively referring to context for explanatory purposes means that one does not drown as deeply in the differences between the two places. For example, preliminary analysis of the empirical results indicate that the division between the common-law system in Australia and the civil-law heritage in Indonesia has no apparent explanatory value in this study and can be safely ignored. That is, the interactions between formal law and informal regulation appear to have little to do with the heritage of the law itself. Meanwhile, the more prominent role of religion in Indonesian social life compared to more secular Australia appears to account for the more commonly observed reference to religious principles in the work arrangements in Yogyakarta.

I do not propose to use the concept of 'legal culture' as an explanatory variable here. Legal culture is an amorphous idea that is usually taken to refer to a complex aggregate set of legal practices, 
cultural patterns and attitudes of legal practitioners and the general population as observed in a certain time and place (Nelken, I997; Cotterrell, 20I0). It may be useful for particular purposes, but it is difficult to define and encompasses various different dimensions (Merry, 2010). Often, legal culture is conveniently used as a residual explanatory factor that is brought into play when everything else has been accounted for (Merry, 20I0). I also agree with Banakar (2009, p. 78) that there are often aspects of context that need to be taken account of, such as the structure of the economy or political regime change, which are not easily described in cultural terms.

Zweigert and Kötz do not explain whether it is possible and, if so, how to prove causation between context and the differences and similarities between the identified solutions to the social problem. It is likely that explanations of the links between the micro-level findings in this project and the wider context can only be speculative, as causation cannot be proven (Cotterrell, 20I0). It may be that a particular norm or law appears to be linked to a particular context but is instead caused by some other factor. Further, contextual factors can rarely be disentangled but rather they act in complex combined ways. For example, it is tempting to draw a link between the creation of the category of 'casual' work as a major form of non-standard employment in Australia and the observation that many informally regulated workers in Melbourne described themselves as being casual workers. However, there is no way of knowing whether there is a causal link between this context and the empirical observations. Hence, any conclusions regarding the causes for the differences and similarities will need to be carefully qualified as to their speculative nature.

\section{Building on the functional approach using 'legal consciousness'}

Frankenberg (1985, p. 438), in his critique of functionalism, as quoted above, stated that there is no place in the functional method for gaining an understanding of law as consciousness or cluster of beliefs, and indeed this is not a step included in Zweigert and Kötz's formula. Frankenberg was writing prior to the growth during the I99os in 'legal consciousness' as a socio-legal concept and comparative tool for understanding the construction and circulation of concepts of law in everyday life. He was basing his comments on doctrinal, rather than empirical, comparative law studies. I take the view that there are no impediments to building on the functional approach to comparison by using a narrowly focused legal consciousness methodology. Given the micro-level nature of the empirical research required to support the functional approach, it would not be possible to combine it with attempts to analyse legal culture or broader legal consciousness methods.

Legal consciousness research methods range from the very broad approach of Ewick and Silbey (I998), where they conducted hundreds of interviews with randomly selected adults and were careful to ask about everyday life rather than directly about law, to more focused approaches that select a particular group of people, such as the environmental activists (Halliday and Morgan, 2013) or welfare recipients (Sarat, I990). Not all scholars follow Ewick and Silbey's choice of not asking directly about law (e.g. Kurkchiyan, 20II). Engel's (2005) research on the legal consciousness of people injured in traffic accidents in Chiangmai, Thailand, perhaps comes closest to focusing on a specific social problem (an injury) and the solutions that injured people seek (law, negotiation, religious ritual, etc.).

This socio-legal comparative project does have the potential to shed light on individual and collective attitudes towards law situated within the boundaries of the research as functionally defined by the social problem and its solutions. The interview questions elicited indications of the attitudes towards law (or 'inner' perspective) and the applicability of law to the social problem of determining work arrangements in restaurants. Of particular comparative interest here are the different narratives that support the distinction between formal and informal labour regulation in the two cities. 
For example, in the Yogyakarta study, many respondents in smaller eateries articulated a very clear and unconcerned view that their situation fell outside the scope of labour law, which they saw as only applying to large companies. In other words, they saw legality in very flexible terms. In Melbourne, some of the interviewees who were working in more informally regulated situations tended to convey a much greater sense of unease about breaking the law and that injustice was occurring. These observations made within different points in the spectrum of formal and informally regulated restaurants do not appear to map easily onto the major narratives of legal consciousness identified by leading researchers (Ewick and Silbey, I998; Halliday and Morgan, 2013), suggesting that narratives expressed within situations of strong normative pluralism need further investigation.

Therefore, setting the external boundaries of the research project through using functional parameters is no obstacle to later developing analysis of interviewees' notions of legality, though one must take a narrowly focused approach to legal consciousness-based analysis. While this is certainly an optional rather than compulsory additional step to successfully employing the functional approach, it does enhance the analytical potential of the present comparative project. It also links closely to the need to gain an 'inner perspective' in order to explore causation, as discussed above. This is certainly not a call for all legal consciousness studies to build on the functional approach, but I do think that it does provide a concrete point of comparability across cases, which studies of legal consciousness or legal culture that try to capture nationwide attitudes and narratives often lack.

\section{Evaluation and policy consequences}

The final step in Zweigert and Kötz's functional approach is to evaluate the findings both critically and normatively and to ask which solutions most effectively respond to the social problem in each location. In the case of this particular comparative project, this step offers the opportunity to address Twining's (2009) critique of the lack of 'justification, legitimation and evaluation' in studies of legal pluralism. As noted, this project is very relevant to the current initiatives of the ILO in promoting the formalisation of informal work around the world. The comparison in this project should shed light on the role of informal norms in regulating work arrangements, the extent to which formal labour law is complemented by, or even undermined by, informal norms and institutions, and the likelihood of effective change through the use of formal labour laws. The normative measure to be used here is the extent to which the 'legal' and 'extra-legal' solutions solve the defined social problem of fulfilling the requirements of the restaurant owner to run their business while providing satisfaction and benefits to workers. It appears that the functional approach to comparison more easily leads to policy implications than wide-ranging legal pluralism studies or comparative socio-legal based on 'legal culture' and other concepts because the analysis is more targeted to a particular social problem.

\section{Conclusion}

This paper set out to evaluate the functional approach as a means of overcoming issues of comparability between empirical data collected in two very different cities. Although there are certainly complexities and limitations inherent to the functional approach, I have argued that overall it does provide a concrete and defensible strategy for undertaking comparison in this particular project on formal labour laws and informal norms in the regulation of restaurant work. Zweigert and Kötz's method provides the basic analytical steps, but there are some additional modifications and explicit acknowledgement of limitations required. For the identification of the social problem, it should be a matter of empirical observation as to whether the problem is similar enough in each place to support functional analysis. Equal weight needs to be given to 
identifying and comparing the 'legal' and 'extra-legal' solutions that arise in relation to a social problem. To avoid making positivist assumptions about the links between law/norms and outcomes, combined outer and inner perspectives should be helpful, though may not entirely prove causality. It should be acknowledged that the search for unbiased common concepts for comparative analysis should be undertaken, but ultimately bias is impossible to eliminate and declarations of researchers' subjective positions should be made. A further limitation to the analysis is that only speculative conclusions will be able to be drawn between the similarities and differences observed and their causal links to the wider social context. It is contended here that research that is delimited by the functional approach can, and indeed should, examine narratives of legal consciousness. This gives further critical understanding of the 'inner perspective' on the social problem and its 'legal' and 'extra-legal' solutions and how these solutions are selected and maintained. Finally, the functional approach should provide clear avenues for normative evaluation and formulation of policy recommendations.

While the functional approach has come under sustained criticism from certain theorists, it seems to me that these theorists have overlooked its clear potential for use in comparative sociolegal research. In particular, the emphasis on identifying both 'legal' and 'extra-legal' solutions to social problems expands the scope of the functional approach beyond its assumed focus on doctrinal comparative law studies. The analytical approach taken in this particular project, with its additional methodological and analytical steps and explicit acknowledgement of limitations, may be usefully replicated in research projects in other contexts.

\section{References}

ADAMS, Maurice and GRIFFITHS, John (20I2) 'Against "Comparative Method": Explaining Similarities and Differences' in Maurice Adams and Jacco Bomhoff (eds) Practice and Theory in Comparative Law. Cambridge: Cambridge University Press, 279-30r.

ANDERSon, Gordon, Cooney, Sean, Gahan, Peter, mahy, Petra, Mao, Lingfeng, mitchell, Richard, o'donnell, Anthony and sutherland, Carolyn (2015) 'Calculating the Protective Strength of Labour Law through "Leximetrics”: A Discussion and Application of Variables, Measures and Purposes'. Paper presented at the Labour Law Research Network (LLRN) Conference, Amsterdam, 25-27 June 2015 .

BAIER, Matthias (2013) 'Relations between Social and Legal Norms' in Matthias Baier (ed.) Social and Legal Norms: Towards a Socio-Legal Understanding of Normativity. Farnham: Ashgate Publishing, 53-70.

BANAKAR, Reza (2009) 'Power, Culture and Method in Comparative Law', International Journal of Law in Context 5(I): 69-85.

BanaKar, Reza (20I5) Normativity in Legal Sociology: Methodological Reflections on Law and Regulation in Late Modernity. Cham: Springer.

BANAKAR, Reza and travers, Max (2005) 'Studying Legal Cultures' in Reza Banakar and Max Travers (eds) Theory and Method in Socio-Legal Research. Oxford: Hart Publishing, 239-244.

BAXI, Upendra (2003) 'The Colonialist Heritage' in Pierre Legrand and Roderick Munday (eds) Comparative Legal Studies: Traditions and Transitions. Cambridge: Cambridge University Press, $46-75$.

BENTON, Lauren (I994) 'Beyond Legal Pluralism: Towards a New Approach to Law in the Informal Sector', Social \& Legal Studies 3: 223-242.

BRAND, Oliver (2007) 'Conceptual Comparisons: Towards a Coherent Methodology of Comparative Legal Studies', Brook Journal of International Law 32(2): 405-466.

сніва, Masaji (I998) 'Other Phases of Legal Pluralism in the Contemporary World', Ratio Juris I I(3): 228-245. 
cooney, Sean, mahy, Petra, mitchell, Richard and gahan, Peter (2014) 'The Evolution of Labor Law in Three Asian Nations: An Introductory Comparative Study', Comparative Labor Law \& Policy Journal 36(I): 23-68.

COTterRell, Roger (2010) 'Conscientious Objection to Assigned Worktasks: A Comment on Relations of Law and Culture', Comparative Labor Law \& Policy Journal 3I: 5I I-522.

COTTERRELl, Roger (20I2) 'Comparative Sociology of Law' in David S. Clark (ed.) Comparative Law and Society. Cheltenham: Edward Elgar, 39-60.

DAvidov, Guy and LANGILLE, Brian (eds) (2006) Boundaries and Frontiers of Labour Law: Goals and Means in the Regulation of Work. Oxford and Portland, OR: Hart Publishing.

Davidov, Guy and LANGILle, Brian (eds) (20I I) The Idea of Labour Law. Oxford: Oxford University Press. DEAKIN, Simon (2010) 'Labor and Employment Laws' in Peter Cane and Herbert M. Kritzer (eds) Oxford

Handbook of Empirical Legal Research. Oxford: Oxford University Press, 308-330.

ENGEL, David M. (2005) 'Globalization and the Decline of Legal Consciousness: Torts, Ghosts and Karma in Thailand', Law and Social Inquiry 30(3): 469-5I4.

ewick, Patricia and Silbey, Susan S. (1998) The Common Place of Law. Chicago and London: University of Chicago Press.

FInKIn, Matthew W. (ed.) (2015) Comparative Labor Law. Cheltenham, UK: Edward Elgar.

FRANKEnBerg, Günter (I985) 'Critical Comparisons: Rethinking Comparative Law', Harvard International Law Journal 26(2): 4I I-455.

FRAZER, Andrew (2014) 'Labour Law, Institutionalist Regulation and the Employing Organisation', International Employment Relations Review 2O(I): 4-26.

FUdGe, Judy, SANKARAn, Kamala and MCCRYSTAL, Shae (eds) (20I2) Challenging the Legal Boundaries of Work Regulation (Onati series). Oxford: Hart.

Galligan, D. J. (2007) Law in Modern Society. Oxford: Oxford University Press.

GUHA-KHASNOBIS, Basudeb, KANBUR, Ravi and OSTROM, Elinor (2006) 'Beyond Formality and Informality'

in Basudeb Guha-Khasnobis, Ravi Kanbur and Elinor Ostrom (eds) Linking the Formal and Informal

Economy: Concepts and Policies. Oxford: Oxford University Press, I-I6.

halliday, Simon and morgan, Bronwen (2013) 'I fought the Law and the Law Won? Legal

Consciousness and the Critical Imagination', Current Legal Problems 66: I-32.

HARRISS-WHITE, Barbara (20I0) 'Work and Wellbeing in Informal Economies: The Regulative Roles of

Institutions of Identity and the State', World Development 38(2): I70-I83.

Hart, H.L.A. (I96I) The Concept of Law. Oxford: Clarendon Press.

HELmKe, Gretchen and Levitsky, Steven (2004) 'Informal Institutions and Comparative Politics: A Research Agenda', Perspectives on Politics 2(4): 725-740.

HUSA, Jaakko (2003) 'Farewell to Functionalism or Methodological Tolerance', Rabels Zeitschrift für Ausländisches und Internationales Privatrecht 67(3):419-447.

international Labour ORganisation (ILO) (2013) The Informal Economy and Decent Work: A Policy Resource Guide Supporting Transitions to Formality. Geneva: ILO.

KelSen, Hans (I 967) Pure Theory of Law, translation from the 2nd revised and enlarged German version by Max Knight. Berkeley: University of California Press.

KuRKChiyan, Marina (20II) 'Perceptions of Law and Social Order: A Cross-National Comparison of

Collective Legal Consciousness', Wisconsin International Law Journal 29: 366-392.

Legrand, Pierre (2003) 'The Same and the Different' in Pierre Legrand and Roderic Munday (eds) Comparative Legal Studies: Traditions and Transitions. Cambridge: Cambridge University Press, 240-3II.

LEYLAND, Peter (2002) 'Oppositions and Fragmentations: In Search of a Formula for Comparative Analysis?' in Andrew Harding and Esin Örücü (eds) Comparative Law in the $2 I^{\text {st }}$ Century. London: Kluwer Law International, 2 I I-233. 
Ludlow, Amy and BLACKHAM, Alysia (eds) (2015) New Frontiers in Empirical Labour Law Research. Oxford: Hart Publishing.

mahy, Petra, mitchell, Richard, tham, Joo-Cheong, Boese, Martina, cooney, Sean and howe, John (forthcoming) 'The Plural Regulation of Work: A Pilot Study of Workers in Yogyakarta, Indonesia'. Research Report.

malinowski, Bronislaw (I926) Crime and Custom in a Savage Society. New York: Harcourt Brace \& Co. and London: Kegan Paul, Trench, Trubner \& Co.

MERRY, Sally Engle (I988) 'Legal Pluralism', Law \& Society Review 22: 869-896.

MERRY, Sally Engle (2010) 'What Is Legal Culture? An Anthropological Perspective', Journal of Comparative Law 5(2): 40-58.

michaels, Ralf (2006) 'The Functional Method of Comparative Law' in Matthias Reimann and Reinhard Zimmerman (eds) Oxford Handbook of Comparative Law. Oxford: Oxford University Press, 340-38r.

mitchell, Richard, mahy, Petra and gahan, Peter (20I4) 'The Evolution of Labour Law in India: An

Overview and Commentary on Regulatory Objectives and Development', Asian Journal of Law and Society I(2): 4I4-453.

MNOOKIN, Robert H. and KoRnHAuser, Lewis (I979) 'Bargaining in the Shadow of the Law: The Case of

Divorce', The Yale Law Journal 88:950-997.

MOORE, Sally Falk (I969) 'Comparative Studies' in Laura Nader (ed.) Law in Culture and Society.

Berkeley: University of California, 337-348.

NELKen, David (ed.) (1997) Comparing Legal Cultures. Aldershot: Dartmouth.

NELKen, David (2005) 'Doing Research into Comparative Criminal Justice' in Reza Banakar and

Max Travers (eds) Theory and Method in Socio-Legal Research. Oxford: Hart Publishing, 245-258.

parker, Christine, scott, Colin, Lacey, Nicola and Bratthwatte, John (2004) 'Introduction' in

Christine Parker, Colin Scott, Nicola Lacey and John Braithwaite (eds) Regulating Law. Oxford:

Oxford University Press.

PUCHALSKA-TYCH, Bogumila and SALTER, Michael (I996) 'Comparing Legal Cultures of Eastern Europe:

the Need for Dialectical Analysis', Legal Studies I6(2):I57-I84.

Ruskola, Teemu (2002) 'Legal Orientalism', Michigan Law Review Ior(I):I79-234.

SAMUel, Geoffrey (2014) An Introduction to Comparative Law Theory and Method. Oxford and Portland,

OR: Hart Publishing.

SARAT, Austin (I990) “... the Law is All Over”: Power Resistance and the Legal Consciousness of the

Welfare Poor', Yale Journal of Law \& the Humanities 2:343-379.

SPORTEL, Terah (2013) 'Agency within a Socially Regulated Labour Market: A Study of Unorganised

Agricultural Labour in Kerala', Geoforum 47:42-52.

tamanaha, Brian Z. (2008) 'Understanding Legal Pluralism: Past to Present, Local to Global', Sydney

Law Review 30: 375-4II.

TEKLÈ, Tzehainesh (2010) 'Labour Law and Worker Protection in the South: An Evolving Tension

between Models and Reality' in Tzehainesh Teklè (ed.) Labour Law and Worker Protection in

Developing Countries. Oxford, Hart and International Labour Office, 3-47.

TSIKATA, Dzodzi (20II) 'Toward a Decent Work Regime for Informal Employment in Ghana: Some

Preliminary Considerations', Comparative Labor Law \& Policy Journal 32(3 I):3 I I-342.

Twining, William (2009) 'Normative and Legal Pluralism: A Global Perspective', Duke Journal of

Comparative and International Law 20: 473-5 I7.

valCKE, Catherine (2012) 'Reflections on Comparative Law Methodology: Getting Inside Contract

Law' in Maurice Adams and Jacco Bomhoff (eds) Practice and Theory in Comparative Law.

Cambridge: Cambridge University Press, 22-48.

Watson, Alan (2000) 'Law out of Context', Edinburgh Law Review 4: I47-I67. 
436 PETRA MAHY

whitman, Alan Q. (2003) 'The Neo-Romantic Turn' in Pierre Legrand and Roderick Munday (eds) Comparative Legal Studies: Traditions and Transitions. Cambridge: Cambridge University Press, 3I 2-344.

zWEIGERT, Konrad and кӧтz, Hein (I998) Introduction to Comparative Law, 3rd edn, translated by Tony Weir. Oxford: Clarendon Press. 